Figure S2. Geometry optimizations and binding energy (B.E., in kcal/mol) calculations on the Water-Acetic acid dimer as a model system of the $\mathrm{O}\left(s p^{3}\right): \rightarrow \mathrm{C}\left(s p^{2}\right)$ donor-acceptor interaction:

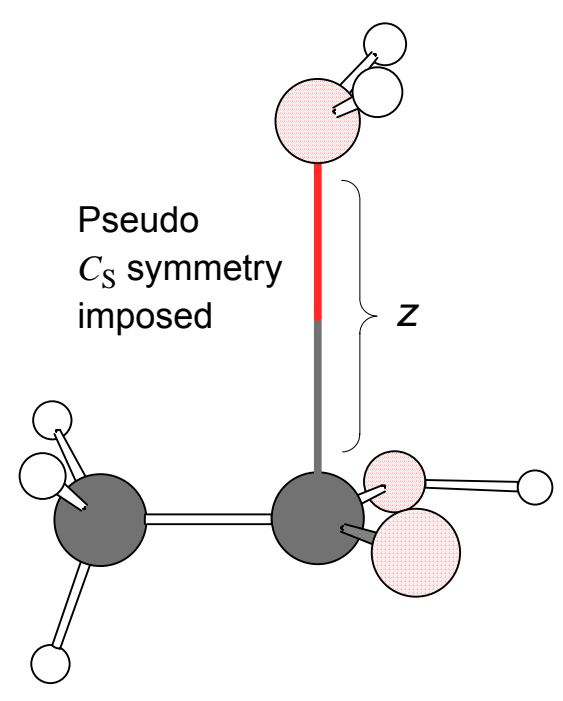

\begin{tabular}{|c|c|c|c|c|c|}
\hline & $\begin{array}{l}\text { MP2I } \\
6-31 G^{*}\end{array}$ & $\begin{array}{l}\text { B3LYPI } \\
6-31 G^{*}\end{array}$ & $\begin{array}{c}\text { MP2/ } \\
6-311+G(2 d, 2 p)\end{array}$ & $\begin{array}{c}\operatorname{CCSD}(\mathrm{T}) I \\
6-311+G(2 d, 2 p)^{a}\end{array}$ & $\begin{array}{c}\text { B3LYPI } \\
6-311+G(2 d, 2 p)\end{array}$ \\
\hline$z(\AA)$ & 2.850 & 2.956 & 2.934 & - & 3.193 \\
\hline B. E. $(\mathrm{kcal} / \mathrm{mol})$ & 2.2 & 3.2 & 1.0 & 3.1 & 2.6 \\
\hline B. E. $(\mathrm{kcal} / \mathrm{mol})$ & 1.9 & 0.9 & 0.9 & 1.6 & 1.6 \\
\hline BSSE-corrected ${ }^{b}$ & & & & & \\
\hline
\end{tabular}

${ }^{a}$ Single-point energy calculations at the MP2/6-311+G(2d,2p) geometries.

${ }^{\mathrm{b}}$ BSSE-corrected values were obtained using the Counterpoise method. 


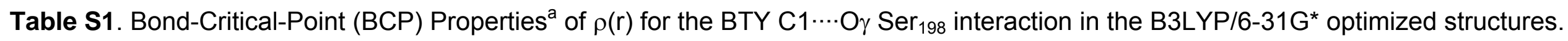
BCP properties were obtained from B3LYP/6-311+G** charge densities.

\begin{tabular}{ccccccc}
\hline & $\begin{array}{c}\rho\left(\mathbf{r}_{\mathbf{c}}\right) \\
(\mathrm{au})\end{array}$ & $\begin{array}{c}\nabla^{2} \rho\left(\mathbf{r}_{\mathbf{c}}\right) \\
(\mathrm{au})\end{array}$ & $\varepsilon$ & $\begin{array}{c}\mathbf{r}_{1} \\
(\AA)\end{array}$ & $\begin{array}{c}\mathbf{r}_{2} \\
(\AA)\end{array}$ & $\begin{array}{c}\mathbf{H}\left(\mathbf{r}_{\mathbf{c}}\right) \\
(\mathrm{au})\end{array}$ \\
\hline acyl & 0.312 & -0.428 & 0.011 & 0.456 & 0.872 & 0.461 \\
TS1 & 0.263 & -0.614 & 0.048 & 0.526 & 0.883 & 0.329 \\
int & 0.239 & -0.500 & 0.043 & 0.559 & 0.907 & 0.263 \\
TS2 & 0.108 & 0.103 & 0.054 & 0.798 & 1.000 & 0.038 \\
prodA & 0.029 & 0.099 & 0.062 & 1.137 & 1.258 & 0.000 \\
TS3 & 0.028 & 0.076 & 0.109 & 1.198 & 1.304 & 0.000 \\
$\operatorname{prodB}^{\text {b }}$ & - & - & - & - & - & -
\end{tabular}

a $\mathrm{r}_{\mathrm{c}}, \rho\left(\mathrm{r}_{\mathrm{c}}\right), \nabla^{2} \rho\left(\mathrm{r}_{\mathrm{c}}\right)$ and $\varepsilon$ stand for the BCP, the electronic density, the Laplacian of the electronic density and ellipticity at the BCP, respectively. $r_{1}$ and $r_{2}$ are the bond path lengths from the critical point to $C$ and $O$ in the $C-O$ bond. $H\left(r_{c}\right)$ is the local energy density. ${ }^{\mathrm{b}} \mathrm{BCP}$ did not exist. 
Table S2. Summary of the RMS Deviations ( $(\AA)$ obtained from the last 500 ps of the BCHE-BTY, BCHE-BTY-Na ${ }^{+}$BCHE-BTY-GOL and BCHE-BTY-CHO MD-LES trajectories.

\begin{tabular}{ccccc}
\hline & BCHE-BTY & BCHE-BTY-Na+ & BCHE-BTY-GOL & BCHE-BTY-CHO \\
\hline protein total & $1.75 \pm 0.04$ & $1.76 \pm 0.05$ & $1.81 \pm 0.05$ & $1.76 \pm 0.04$ \\
protein backbone & $1.35 \pm 0.06$ & $1.38 \pm 0.06$ & $1.39 \pm 0.06$ & $1.37 \pm 0.06$ \\
gorge & $1.62 \pm 0.09$ & $1.59 \pm 0.05$ & $1.55 \pm 0.06$ & $1.52 \pm 0.06$ \\
$\Omega$-loop (Cys 65 -Cys92) & $1.31 \pm 0.09$ & $1.22 \pm 0.08$ & $1.38 \pm 0.09$ & $1.28 \pm 0.08$ \\
$\Omega$-loop backbone (Cys $65-$ Cys $\left._{92}\right)$ & $0.81 \pm 0.07$ & $0.81 \pm 0.08$ & $0.81 \pm 0.08$ & $0.84 \pm 0.09$ \\
acyl-loop (Pro $281-$ Ser $_{287}$ ) & $3.17 \pm 0.18$ & $3.10 \pm 0.11$ & $2.98 \pm 0.18$ & $2.78 \pm 0.26$ \\
acyl-loop backbone (Pro $281-$ Ser $\left._{287}\right)$ & $1.32 \pm 0.07$ & $1.25 \pm 0.06$ & $1.34 \pm 0.06$ & $1.36 \pm 0.10$ \\
gorge rim & $2.38 \pm 0.17$ & $2.53 \pm 0.09$ & $2.18 \pm 0.12$ & $2.21 \pm 0.19$ \\
\hline
\end{tabular}


Table S3. Average values $(\AA)$ for the radii of accessibility corresponding to important functional groups through the "main door" during the BCHE-BTY, BCHE-BTY-Na ${ }^{+}$BCHE-BTY-GOL and BCHE-BTY-CHO MD-LES trajectories. Values in italics were computed after having removed the coordinates of the BTY moiety (see further details in Suárez, D.; Field, M.J. Proteins: Structure, Function and Bioinformatics, 2005, 59, 104-117).

\begin{tabular}{|c|c|c|c|c|c|}
\hline Groups & X-ray & BCHE-BTY & BCHE-BTY-Na+ & BCHE-BTY-GOL & BCHE-BTY-CHO \\
\hline $\mathrm{Ser}_{198} \mathrm{O} \gamma$ & 2.2 & $2.18 \pm 0.08$ & $2.13 \pm 0.06$ & $2.14 \pm 0.07$ & $2.16 \pm 0.08$ \\
\hline \multirow[t]{2}{*}{$\mathrm{Glu}_{197}-\mathrm{COO}$} & 2.5 & $2.70 \pm 0.21$ & $2.76 \pm 0.25$ & $2.60 \pm 0.18$ & $2.88 \pm 0.17$ \\
\hline & & $2.98 \pm 0.16$ & $2.99 \pm 0.18$ & $2.95 \pm 0.13$ & $3.11 \pm 0.14$ \\
\hline Gly $_{116}$ & 3.4 & $3.19 \pm .0 .16$ & $3.26 \pm 0.22$ & $3.11 \pm 0.15$ & $3.32 \pm 0.18$ \\
\hline $\mathrm{Tyr}_{128}-\mathrm{O} \eta$ & 2.0 & $2.41 \pm 0.22$ & $2.52 \pm 0.28$ & $2.33 \pm 0.19$ & $2.57 \pm 0.24$ \\
\hline Phe $_{395}$ Ring & 2.1 & $2.08 \pm 0.10$ & $1.98 \pm 0.10$ & $2.03 \pm 0.10$ & $2.02 \pm 0.11$ \\
\hline $\mathrm{Asp}_{70}-\mathrm{COO}$ & 3.4 & $3.83 \pm 0.43$ & $3.96 \pm 0.50$ & $4.00 \pm 0.44$ & $3.77 \pm 0.50$ \\
\hline BTY-COO & $\sim$ & $3.12 \pm 0.16$ & $3.08 \pm 0.21$ & $3.11 \pm 0.17$ & $3.21 \pm 0.18$ \\
\hline
\end{tabular}


Table S4. Relative energy components and free energy corrections (in kcal/mol) of the "small QM models" involved in the deacylation process of BuChE. The MM-PB energy terms correspond to average values derived from 100 snapshots extracted during the last 500 ps of the BCHE-BTY-Na MD-LES simulation and post-processed according to the MM-PB computational scheme. Standard error of the mean values are given in parentheses. All values are in $\mathrm{kcal} / \mathrm{mol}$.

\begin{tabular}{|c|c|c|c|c|c|c|c|}
\hline Structure & $\begin{array}{c}\text { B3LYP/6-311+G** } \\
+ \text { ZPVE }^{a}\end{array}$ & $G_{\mathrm{MM}-\mathrm{PB}}{ }^{\mathrm{b}}$ & $E_{M M}{ }^{c}$ & $E_{\text {elec }}{ }^{\mathrm{d}}$ & $E_{v d W}{ }^{\mathrm{d}}$ & $E_{\text {int }}{ }^{\mathrm{d}}$ & $\Delta G^{\mathrm{e}}$ \\
\hline acyl & 0.0 & 0.0 & 0.0 & 0.0 & 0.0 & 0.0 & 0.0 \\
\hline TS1 & 4.8 & $9.0(0.6)$ & $7.4(0.6)$ & $8.0(1.0)$ & $-0.1(0.6)$ & $-0.5(0.1)$ & 13.8 \\
\hline int & 1.3 & $4.7(0.8)$ & $3.0(0.8)$ & $8.6(1.1)$ & $-1.1(0.9)$ & $-4.5(0.2)$ & 6.0 \\
\hline prodA & 9.7 & $-2.4(0.9)$ & $-4.6(0.9)$ & $-2.9(1.4)$ & $1.5(1.0)$ & $-3.3(0.2)$ & 7.3 \\
\hline prodB & -14.0 & $18.0(1.0)$ & $24.8(1.0)$ & $25.0(0.8)$ & $1.9(1.0)$ & $-3.0(0.2)$ & 4.0 \\
\hline
\end{tabular}


Table S5. Relative energy components and free energy corrections (in kcal/mol) of the "small QM models" involved in the deacylation process of BuChE. The MM-PB energy terms correspond to average values derived from 100 snapshots extracted during the last 500 ps of the BCHE-BTY-GOL MD-LES simulation and post-processed according to the MM-PB computational scheme. Standard error of the mean values are given in parentheses. All values are in $\mathrm{kcal} / \mathrm{mol}$.

\begin{tabular}{|c|c|c|c|c|c|c|c|}
\hline Structure & $\begin{array}{c}\text { B3LYP/6-311+G** } \\
+ \text { ZPVE }^{a}\end{array}$ & $G_{\mathrm{MM-PB}}{ }^{\mathrm{b}}$ & $E_{M M}{ }^{\mathrm{C}}$ & $E_{\text {elec }}{ }^{\mathrm{d}}$ & $E_{v d W}{ }^{d}$ & $E_{\text {internal }}{ }^{\mathrm{d}}$ & $\Delta G^{\mathrm{e}}$ \\
\hline acyl & 0.0 & 0.0 & 0.0 & 0.0 & 0.0 & 0.0 & 0.0 \\
\hline TS1 & 4.8 & $8.6(0.5)$ & $7.6(0.6)$ & $9.9(0.8)$ & $-0.6(0.4)$ & $-1.7(0.1)$ & 13.4 \\
\hline int & 1.3 & $2.6(0.6)$ & $2.6(0.7)$ & $10.0(1.0)$ & $-1.4(0.6)$ & $-6.1(0.2)$ & 3.9 \\
\hline TS2 & 9.3 & $-2.0(0.6)$ & $-2.4(0.6)$ & $4.4(1.0)$ & $-1.4(0.6)$ & $-5.3(0.2)$ & 7.3 \\
\hline prodA & 9.7 & $-4.2(0.6)$ & $-6.5(0.6)$ & $-3.0(0.9)$ & $0.3(0.6)$ & $-3.7(0.2)$ & 5.5 \\
\hline prodB & -14.0 & $21.7(0.8)$ & $30.6(0.9)$ & $32.5(1.4)$ & $1.3(0.7)$ & $-3.2(0.2)$ & 7.7 \\
\hline
\end{tabular}

${ }^{\text {a }}$ From single-point calculations on the small QM models including the approximate ZPVE correction (see text for details).

${ }^{\mathrm{b}}$ Free energy correction to the QM energies obtained from MM-PB calculations: $G_{\mathrm{MM}-\mathrm{PB}}=E_{\mathrm{MM}}+\Delta \Delta G_{\text {solv }}$

${ }^{c}$ Molecular mechanical correction to the QM energies

${ }^{\mathrm{d}}$ Electrostatic, van der Waals, and internal (bond-angle-torsional) energy components of the MM energy correction

${ }^{\mathrm{e}}$ Approximate free energy of the small QM models in the enzyme: $\Delta G \approx \Delta E_{\mathrm{B} 3 \mathrm{LYP} / 6-311+\mathrm{G}^{* *}}+G_{\mathrm{MM}-\mathrm{PB}}$ 
Table S6. Relative energy components and free energy corrections (in kcal/mol) of the "small QM models" involved in the deacylation process of BuChE. The MM-PB energy terms correspond to average values derived from 100 snapshots extracted during the last 500 ps of the BCHE-BTY-CHO MD-LES simulation and post-processed according to the MM-PB computational scheme. Standard error of the mean values are given in parentheses. All values are in $\mathrm{kcal} / \mathrm{mol}$.

\begin{tabular}{|c|c|c|c|c|c|c|c|}
\hline Structure & $\begin{array}{c}\text { B3LYP/6-311+G** } \\
+ \text { ZPVE }^{a}\end{array}$ & $G_{\mathrm{MM-PB}}{ }^{\mathrm{b}}$ & $E_{M M}{ }^{c}$ & $E_{\text {elec }}{ }^{\mathrm{d}}$ & $E_{v d W}{ }^{\mathrm{d}}$ & $E_{\text {internal }}{ }^{\mathrm{d}}$ & $\Delta G^{\mathrm{e}}$ \\
\hline acyl & 0.0 & 0.0 & 0.0 & 0.0 & 0.0 & 0.0 & 0.0 \\
\hline TS1 & 4.8 & $8.3(0.5)$ & $7.6(0.6)$ & $7.9(0.9)$ & $0.6(0.5)$ & $-0.9(0.1)$ & 13.1 \\
\hline int & 1.3 & $4.8(0.6)$ & $5.5(0.7)$ & $10.1(1.0)$ & $0.4(0.6)$ & $-4.9(0.2)$ & 6.1 \\
\hline ProdA & 9.7 & $-5.2(0.7)$ & $-7.1(0.8)$ & $-6.3(1.1)$ & $2.3(0.8)$ & $-3.2(0.2)$ & 4.5 \\
\hline ProdB & -14.0 & $20.0(0.8)$ & $29.1(0.8)$ & $30.4(1.2)$ & $1.7(0.7)$ & $-3.0(0.2)$ & 6.0 \\
\hline $\begin{array}{l}{ }^{c} \mathrm{M} \\
{ }^{\mathrm{d}} \mathrm{E} \\
{ }^{\mathrm{e}} \mathrm{A}\end{array}$ & $\begin{array}{l}\text { single-point calculat } \\
\text { nergy correction to } \\
\text { ular mechanical cor } \\
\text { sstatic, van der Waa } \\
\text { ximate free energy }\end{array}$ & $\begin{array}{l}\text { on the small } \\
\text { QM energies } \\
\text { on to the QM } \\
\text { nd internal (b } \\
\text { e small QM m }\end{array}$ & $\begin{array}{l}\text { odels includi } \\
\text { ed from MM-I } \\
\text { es } \\
\text { ngle-torsiona } \\
\text { in the enzym }\end{array}$ & $\begin{array}{l}\text { approximat } \\
\text { culations: } G \\
\text { gy compon€ } \\
\approx \Delta E_{\text {B3LYP/6-3 }}\end{array}$ & $\begin{array}{l}\text { correction } \\
E_{\mathrm{MM}}+\Delta \Delta G_{\mathrm{s}} \\
\text { the MM en } \\
G_{\mathrm{MM}-\mathrm{PB}}\end{array}$ & for details). & \\
\hline
\end{tabular}




\section{Validating the MM-PB approach}

\section{LES simulations}

The convenience of following the LES methodology to generate an ensemble of enzymesubstrate configurations prior to the MM-PB calculations can be seen by comparing data in Tables 3 and S7. In Table S7 we report results of MM-PB calculations carried out on snapshots extracted from a standard (i.e., non-LES) MD simulation in which the reactive region was modelled in the int configuration. The predicted $\Delta G$ energy profile in Table S7 is clearly biased towards the int structure, which is predicted to be $-10.1 \mathrm{kcal} / \mathrm{mol}$ more stable than the initial acyl structure. A careful examination of data in Table S7 shows that the internal and $\mathrm{vdW}$ contributions to the $\mathrm{MM}$ energy are around $9 \mathrm{kcal} / \mathrm{mol}$ more favourable for the structures int, TS2, prodA and prodB than for acyl and TS1. This means that the protein and solvent environment is much more adapted to "solvate" int-like structures than the acyl-enzyme. In contrast, data in Table 3, which were obtained from the MD-LES simulation, shows that the internal and vdW energy terms are smaller and tend to cancel each other so that the global MM energy is largely dominated by the electrostatic terms.

\section{Atomic charges}

Clearly, the atomic charges for the QM-region are critical parameters in the MM-PB calculations. In principle the use of the RESP methodology and the AMBER force field ensures that electrostatic interactions between all atoms of the enzymatic system are treated on an equal basis. To be consistent with the AMBER force-field, RESP charges for the QM-region were fitted to reproduce the electrostatic potential at the $\mathrm{HF} / 6-31+\mathrm{G}^{*}$ level. However, other authors have noticed that it is not clear a priori if charge models based on HF electrostatic potentials in the gas-phase can be trusted for the estimation of free 
energies.(50) Hence, we decided to explore the dependence of the MM-PB calculations upon different charge models.

Table S8 summarizes the results obtained from MM-PB calculations using RESP charges derived at the $\mathrm{B} 3 \mathrm{LYP} / 6-31+\mathrm{G}^{*}$ level. With respect to data in Table 1 , we see that the $G_{\text {MM-PB }}$ terms are quite similar and that the relative stability of the TS1, int, TS2, prodA and prodB configurations is qualitatively the same. There are, however, some noteworthy changes. For example, with RESP DFT charges, the rate determining energy barrier (TS1) is $\sim 3 \mathrm{kcal} / \mathrm{mol}$ lower than with HF RESP charges and prodA is more stable than prodB. Although it is not clear which charges, HF or DFT, should be more reliable for our particular problem, the differences between the corresponding MM-PB calculations are not large. Moreover, the results in Tables 3 and S8 show that the MM-PB scheme is quite robust regardless of the level of theory employed to derive the gas-phase RESP charges.

In principle force fields whose atomic charges are determined using gas-phase quantum mechanical calculations could fail to represent properly the polarization effects that arise in the condensed phase. However, experience with the AMBER force field suggests that HF/6-31G* RESP atomic charges implicitly include the solvent polarization effect, at least to some extent, because they systematically overestimate dipole moments, much like the charges in point-charge water models.(51) Nevertheless, to compare the effect of gas-phase vs. condensed-phase charges on the MM-PB calculations, a set of HF/6-31+G* RESP charges were obtained by means of SCRF calculations on the gasphase QM geometries using the PCM model included in Gaussian03. A value of 20 for the dielectric constant of the surrounding continuum was chosen to simulate an environment of intermediate polarity.

Table S9 summarizes the results obtained from MM-PB calculations using the HF/6$31+G^{*}$ SCRF RESP charges and reports the computed dipole moments for each "QM model". With respect to the data in Table 1, we see that the $G_{\text {MM-PB }}$ terms for the TS2 and 
prodB "QM models" are different because the MM-PB calculations with the RESP SCRF charges predict that TS2 and prodB should be significantly stabilized by environmental effects (10.5 and $4.5 \mathrm{kcal} / \mathrm{mol}$, respectively) in contrast with the results obtained with the gas-phase RESP charges. The relative stabilities of the other structures (acyl, TS1, int and prodA) are less affected by the choice of the RESP charges. The source of this difference in the MM-PB SCRF results is twofold: (a) an overpolarization effect exerted by the solvent continuum, which exaggerates the charges of the solvent-exposed atoms resulting in more hydrophilic structures. This effect is shown by the values of the corresponding SCRF dipole moments, which are larger than the gas-phase ones for all structures except prodB (see Table S9); (b) the large variability in the polarity and in the solvent accessibility of the charged groups along the series of "QM models", which makes the overpolarization effect act unevenly on equivalent atoms in the different structures. It should also be noted that the SCRF methodologies are empirical models that depend on many parameters (solvent properties, atomic radii, etc.) and that these can also influence significantly the values of the atomic charges. Because of these findings and the way in which the AMBER force-field (parm94) is parametrized, we conclude that using HF/6$31+G^{*} P C M$ charges in the MM-PB calculations is not consistent with the representation of the atomic charges in the enzymatic system that surrounds the "QM models". 
Table S7. Relative energy components of the "small QM models" involved in the deacylation process of BuChE. The various energy terms correspond to average values derived from 50 snapshots extracted during 250 ps of the BCHE-BTY MD simulation (LES was not applied) and post-processed according to the MM-PB computational scheme. Standard error of the mean values are given in parentheses. All values are in $\mathrm{kcal} / \mathrm{mol}$.

\begin{tabular}{|c|c|c|c|c|c|c|c|}
\hline Structure & $\begin{array}{c}\text { B3LYP/6-311+G** } \\
+ \text { ZPVE }^{a}\end{array}$ & $G_{\mathrm{MM-PB}}{ }^{\mathrm{b}}$ & $E_{M M}{ }^{\mathrm{c}}$ & $E_{\text {elec }}{ }^{\mathrm{d}}$ & $E_{v d W}{ }^{\mathrm{d}}$ & $E_{\text {int }}{ }^{\mathrm{d}}$ & $\Delta G^{\mathrm{e}}$ \\
\hline acyl & 0.0 & 0.0 & 0.0 & 0.0 & 0.0 & 0.0 & 0.0 \\
\hline TS1 & 4.8 & $6.7(0.7)$ & $6.0(0.8)$ & $8.3(1.3)$ & $0.4(0.8)$ & $-2.7(0.2)$ & 11.5 \\
\hline int & 1.3 & $-11.4(0.7)$ & $-11.7(1.0)$ & $7.6(2.1)$ & $-9.5(1.3)$ & $-9.8(0.4)$ & -10.1 \\
\hline prodA & 9.7 & $-13.1(1.0)$ & $-16.3(1.2)$ & $-3.3(2.2)$ & $-5.2(1.4)$ & $-7.7(0.3)$ & -3.4 \\
\hline prodB & -14.0 & $9.2(0.9)$ & $16.2(1.2)$ & $27.5(2.1)$ & $-2.7(1.4)$ & $-8.6(0.4)$ & -4.8 \\
\hline $\begin{array}{l}{ }^{c} \mathrm{M} \\
{ }^{\mathrm{d}} \mathrm{E} \\
{ }^{\mathrm{e}} \mathrm{A}\end{array}$ & $\begin{array}{l}\text { single-point calculat } \\
\text { nergy correction to } \\
\text { llar mechanical cor } \\
\text { static, van der Waa } \\
\text { ximate free energy }\end{array}$ & $\begin{array}{l}\text { on the small } \\
\text { QM energies } \\
\text { ion to the QM } \\
\text { and internal (b } \\
\text { ne small QM m }\end{array}$ & $\begin{array}{l}\text { odels includ } \\
\text { ed from MM- } \\
\text { ies } \\
\text { ingle-torsion }\end{array}$ & $\begin{array}{l}\text { approximat } \\
\text { culations: } G \\
\text { gy compon }\end{array}$ & $\begin{array}{l}\text { correction (s } \\
{ }_{\mathrm{MM}}+\Delta \Delta G_{\text {solv }} \\
\text { he MM energ } \\
G_{\mathrm{MM}-\mathrm{PB}}\end{array}$ & for details). & \\
\hline
\end{tabular}


Table S8. Relative energy components and free energy corrections (in kcal/mol) to the "small QM models" involved in the deacylation process of BuChE. Relative values are given with respect to the acyl-enzyme structure. The various energy terms correspond to average values derived from 100 snapshots extracted during the last 500 ps of the BCHE-BTY MD-LES simulation and post-processed according to the MM-PB computational scheme and using B3LYP/6-31+G* RESP charges. Standard error of the mean values are given in parentheses. All values are in $\mathrm{kcal} / \mathrm{mol}$.

\begin{tabular}{|c|c|c|c|c|c|}
\hline Structure & $\begin{array}{c}\text { B3LYP/6-311+G** } \\
+ \text { ZPVE }^{a}\end{array}$ & $G_{M M-P B}^{b}$ & $E_{M M}{ }^{c}$ & $E_{\text {elec }}{ }^{\mathrm{d}}$ & $\Delta G^{\mathrm{e}}$ \\
\hline acyl & 0.0 & 0.0 & 0.0 & 0.0 & 0.0 \\
\hline TS1 & 4.8 & $7.8(0.5)$ & $6.2(0.6)$ & $4.6(1.0)$ & 9.6 \\
\hline int & 1.3 & $5.2(0.6)$ & $4.5(0.7)$ & $8.5(1.3)$ & 6.5 \\
\hline TS2 & 9.3 & $-0.1(0.6)$ & $-0.6(0.7)$ & $3.5(1.2)$ & 9.2 \\
\hline prodA & 9.7 & $-0.9(0.6)$ & $-3.2(0.7)$ & $-0.4(1.2)$ & 8.8 \\
\hline prodB & -14.0 & $23.7(0.6)$ & $31.4(0.8)$ & $31.4(1.4)$ & 9.7 \\
\hline
\end{tabular}

\footnotetext{
${ }^{a}$ From single-point calculations on the small QM models including the approximate ZPVE correction (see text for details).

${ }^{\mathrm{b}}$ Free energy correction to the QM energies obtained from MM-PB calculations: $G_{\mathrm{MM}-\mathrm{PB}}=E_{\mathrm{MM}}+\Delta \Delta G_{\text {solv }}$

${ }^{\mathrm{c}}$ Molecular mechanical correction to the QM energies

dElectrostatic energy component of the MM energy correction

${ }^{\mathrm{e}}$ Approximate free energy of the small QM models in the enzyme: $\Delta G \approx \Delta E_{\mathrm{B3LY} / 6-311+\mathrm{G}^{* *}}+G_{\mathrm{MM}-\mathrm{PB}}$
} 
Table S9. Relative energy components and free energy corrections (in kcal/mol) to the "small QM models" involved in the deacylation process of BuChE. Relative values are given with respect to the acyl-enzyme structure. The various energy terms correspond to average values derived from 100 snapshots extracted during the last 500 ps of the BCHE-BTY MD-LES simulation and post-processed according to the MM-PB computational scheme and using HF/6-31+G* SCRF (PCM, $\varepsilon=20)$ RESP charges. Standard error of the mean values are given in parentheses.

\begin{tabular}{|c|c|c|c|c|c|c|c|}
\hline Structure & $\begin{array}{c}\text { B3LYP/6-311+G** } \\
+ \text { ZPVE }\end{array}$ & $G_{\mathrm{MM}-\mathrm{PB}}^{b}$ & $E_{\mathrm{MM}}{ }^{c}$ & $E_{\text {elec }}{ }^{d}$ & $\Delta G^{e}$ & $\begin{array}{c}\mu \\
\text { gas-phase }^{f}\end{array}$ & $\stackrel{\mu}{\mu}$ \\
\hline acyl & 0.0 & 0.0 & 0.0 & 0.0 & 0.0 & 17.7 & 19.5 \\
\hline TS1 & 4.8 & $7.5(0.7)$ & $6.5(0.8)$ & $6.3(1.2)$ & 12.3 & 11.5 & 14.0 \\
\hline int & 1.3 & $1.5(0.8)$ & $0.9(0.8)$ & $5.0(1.2)$ & 2.8 & 9.9 & 12.4 \\
\hline TS2 & 9.3 & $-10.5(0.7)$ & $-10.6(0.7)$ & $-6.8(1.3)$ & -1.2 & 12.6 & 14.8 \\
\hline $\operatorname{prod} A$ & 9.7 & $-6.1(0.7)$ & $-9.4(0.8)$ & $-5.5(1.3)$ & 3.6 & 18.3 & 19.8 \\
\hline prodB & -14.0 & $-4.5(0.7)$ & $5.7(0.9)$ & $9.7(1.6)$ & -18.5 & 9.7 & 8.9 \\
\hline
\end{tabular}

${ }^{a}$ From single-point calculations on the small QM models including the approximate ZPVE correction (see text for details).

${ }^{\mathrm{b}}$ Free energy correction to the QM energies obtained from MM-PB calculations: $G_{\mathrm{MM}-\mathrm{PB}}=E_{\mathrm{MM}}+\Delta \Delta G_{\text {solv }}$

${ }^{\mathrm{c}}$ Molecular mechanical correction to the QM energies

${ }^{\mathrm{d}}$ Electrostatic energy component of the MM energy correction

${ }^{\text {e }}$ Approximate free energy of the small QM models in the enzyme: $\Delta G \approx \Delta E_{\mathrm{B} 3 \mathrm{LYP} / 6-311+\mathrm{G}^{* *}}+G_{\mathrm{MM}-\mathrm{PB}}$

${ }^{\mathrm{f}} \mathrm{HF} / 6-31+\mathrm{G}^{*}$ dipole moments of the small "QM models" in Debyes. 
QM and MM-PB Calculations of Intramolecular Anhydride Formation

The combination of MD-LES simulations and MM-PB calculations is only suitable to account for environmental effects when the reacting groups are in the same solvent cage and solvent molecules do not participate in the reaction. To further validate the reliability of our computational approach, we investigated the intramolecular $\mathrm{S}_{\mathrm{N}} 2$ reaction of a phenol succinate monoester to give a cyclic anhydride and a phenolate anion (see Scheme S1). This process is one of many possible reference reactions in aqueous solution for the enzymatic hydrolysis of the acyl-enzyme intermediate catalyzed by the BuChE enzyme. In the past this reaction was investigated both experimentally and computationally to ascertain the kinetic effect of conformational compression on intramolecular catalysis of ester bond hydrolysis $(52,53)$

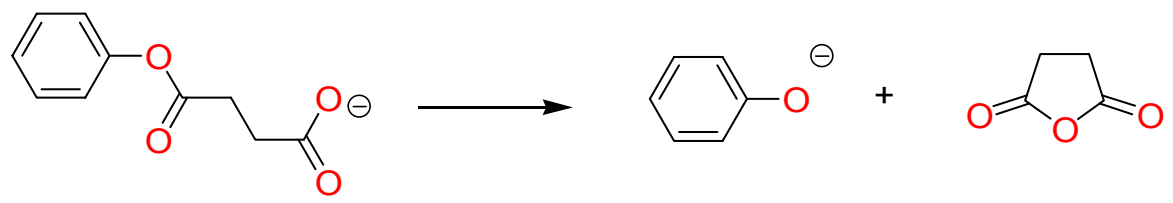

succinate monoester

\section{Scheme S1}

The critical structures involved in the reaction of the succinate monoester were located on the B3LYP/6-31G* PES taking into account solvent effects with the solvent continuum model (PB-SCRF) implemented in the Jaguar program $\left(\varepsilon_{r}=80\right)$. The critical structures were characterized by means of numerical Hessian calculations at the B3LYP/6-31G* PB-SCRF level. In addition, thermal corrections to the solute free energy were computed using the Hessian matrices. Both the electronic and solvation energies for all the structures were refined by means of single point calculations using the 6$311+G(d, p)$ basis set and the B3LYP PB-SCRF method. 
Figure S3. B3LYP/6-31G* critical structures involved in the reaction of the succinate monoester. Selected interatomic distances are in $\AA$.
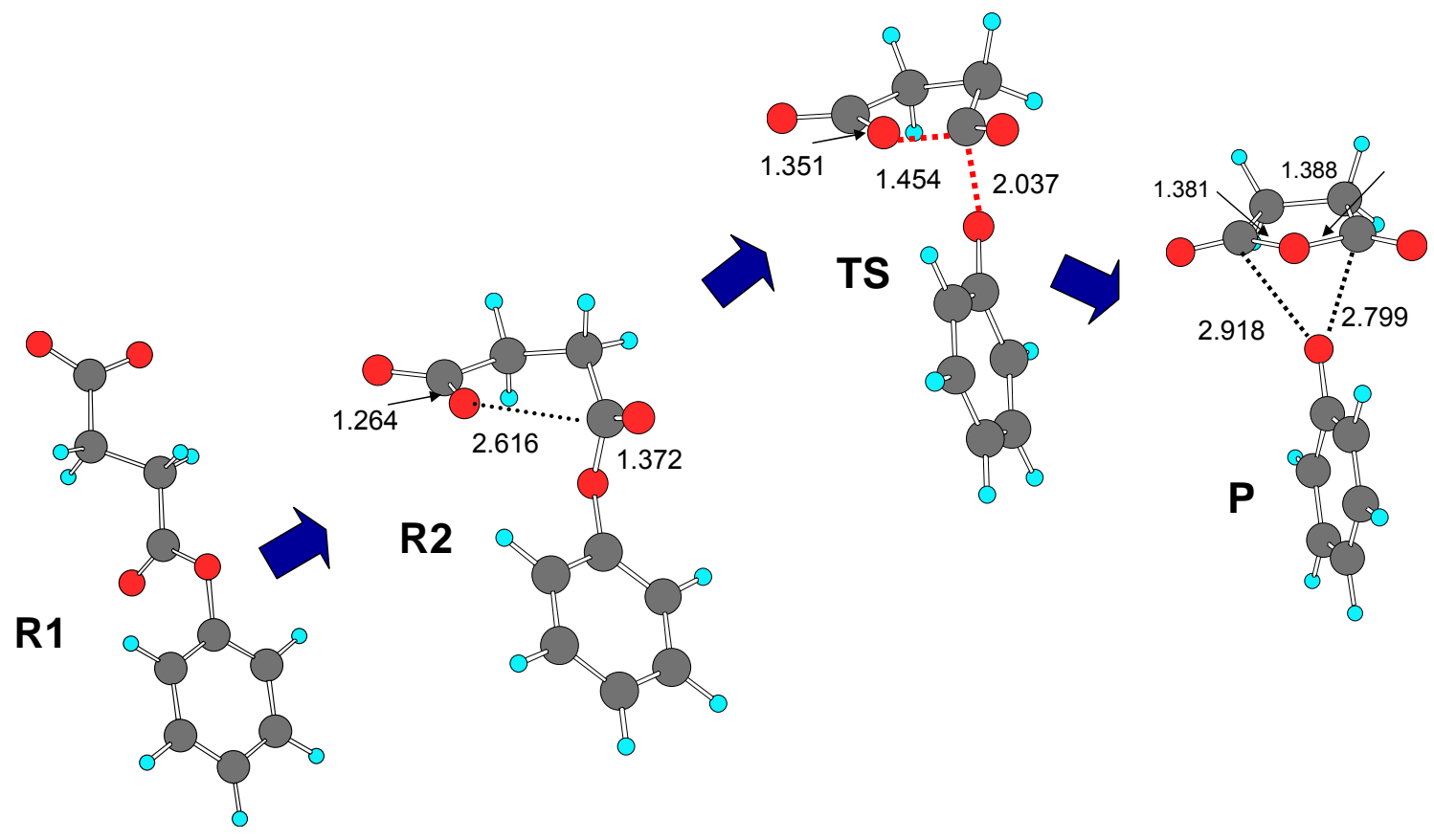

According to our QM calculations, the most favourable conformation of the succinate monoester molecule in aqueous solution is an extended one (R1). We also located a more compact structure (R2), $3.1 \mathrm{kcal} / \mathrm{mol}$ less stable than $\mathbf{R} \mathbf{1}$, in which the attacking $\mathrm{O}$ atom is at only $2.61 \AA$ from the carbonylic $\mathrm{C}$ atom (see Figure S3). From R2 the intramolecular reaction occurs in a single step passing through a transition structure (TS) characterized by asymmetric forming and breaking C-O bonds of lengths 1.45 and $2.04 \AA$, respectively. This structure is connected to a product complex $(\mathbf{P})$ in which the negatively charged $\mathrm{O}$ atom of the phenolate molecule establishes non-covalent $\mathrm{C} \cdots \mathrm{O}$ donor-acceptor interactions with the two carbonylic $\mathrm{C}$ atoms of the anhydride group. The computed free energies of the TS and $\mathbf{P}$ structures with respect to $\mathbf{R} 2$ are 19.5 and 12.5 
$\mathrm{kcal} / \mathrm{mol}$, respectively (see Table S10). The rate determining free energy barrier with respect to $\mathbf{R} \mathbf{1}$ amounts to $22.6 \mathrm{kcal} / \mathrm{mol}$. This theoretical prediction compares quite well with the experimental $\Delta G^{\ddagger}$ value of $20.2 \mathrm{kcal} / \mathrm{mol}$ in $50 / 50(\mathrm{v} / \mathrm{v})$ water-dioxane solution.(52)

Table S10. Relative energy components and free energy corrections (in $\mathrm{kcal} / \mathrm{mol}$ ) of the QM critical structures involved in the intramolecular $\mathrm{SN}_{2}$ reaction of the succinate monoester in aqueous solution. The MM-PB energy terms correspond to average values derived from 100 snapshots extracted from a 1.0 ns MD-LES simulation and postprocessed according to the MM-PB computational scheme. Standard error of the mean $G_{\mathrm{MM}-\mathrm{PB}}$ values are given in parentheses. All values are in $\mathrm{kcal} / \mathrm{mol}$.

\begin{tabular}{|c|c|c|c|c|}
\hline Structure & $\begin{array}{c}\Delta E_{\mathrm{B} 3 \mathrm{LYP}}+ \\
G_{\text {therm }}\end{array}$ & $\begin{array}{c}\Delta \Delta G_{\text {solv }}^{\mathrm{b}} \\
\text { QM SCRF }\end{array}$ & $G_{\mathrm{MM}-\mathrm{PB}}{ }^{\mathrm{c}}$ & $\Delta G^{\mathrm{d}}$ \\
\hline R1 & 1.4 & -4.5 & -- & -3.1 \\
\hline R2 & 0.0 & 0.0 & 0.0 & 0.0 \\
\hline TS & 6.8 & 12.7 & $12.9(1.0)$ & 19.5 \\
\hline $\mathbf{P}$ & 1.2 & 11.3 & $12.5(1.0)$ & 12.5 \\
\hline $\begin{array}{l}{ }^{\mathrm{a}} \mathrm{Fr} \\
{ }^{31 \mathrm{C}} \\
{ }^{\mathrm{b}} \mathrm{Re} \\
{ }^{\mathrm{c}} \mathrm{Fre} \\
{ }^{\mathrm{d}} \mathrm{QN}\end{array}$ & $\begin{array}{l}\text { ngle-point B3 } \\
\text { mal correctio } \\
\text { solvation en } \\
\text { ergy correctio } \\
\text { energy in ac }\end{array}$ & $\begin{array}{l}-311+G^{* *} \text { cal } \\
\text { ree energy. } \\
\text { s evaluated a } \\
\text { e QM energi } \\
\text { solution: } \Delta G\end{array}$ & $\begin{array}{l}\text { ons on the QN } \\
33 \mathrm{LYP} / 6-311+ \\
\text { ained from } \mathrm{Mn} \\
3 \mathrm{LYP}+G_{\text {therm }}+\end{array}$ & $\begin{array}{l}\text { רcluding } \\
\text { level. } \\
\text { lations. } \\
\text { I-SCRF) }\end{array}$ \\
\hline
\end{tabular}

The electronic energies $\left(\Delta E_{B 3 L Y P}\right)$ and solvation free energy $\left(\Delta \Delta G_{\text {solv }}\right)$ contributions to the QM free energies for the series of critical structures $\mathbf{R} \mathbf{1}, \mathbf{R} \mathbf{2}, \mathbf{T S}$ and $\mathbf{P}$ are collected in Table S10. These values show that solute-solvent interactions disfavour 
significantly the reactive process. For example, the relative solvation energies of TS and P with respect to $\mathbf{R} 2$ are 12.7 and $11.3 \mathrm{kcal} / \mathrm{mol}$, respectively.

To find out if the MM-PB calculations can give a similar description of the solutesolvent interactions along the reaction profile to that provided by the QM PB-SCRF calculations, we built MM representations (AMBER-like) of the $\mathbf{R 2}$, TS and $\mathbf{P}$ structures using the RESP HF/6-31+G* atomic charges. Then we carried out a $1.5 \mathrm{MD}-\mathrm{LES}$ simulation of the succinate monoester solvated by a periodic box containing 3578 TIP3P water molecules. During the simulation the MM representations of $\mathbf{R 2}$, TS and $\mathbf{P}$ were treated as "LES copies" while their internal geometry was kept frozen by applying RMSD constraints. One hundred snapshots were extracted from the MD-LES trajectory taking only the coordinates of the solute surrounded by a solvent cap of 1000 water molecules (see Figure S4). Subsequently, we carried out MM-PB energy calculations on selected snapshots to estimate the average free-energy corrections that take into account the environmental effects along the reaction coordinate (the computational details of the MM-PB calculations were identical to those employed for the BuChE systems). The resulting average values of the MM-PB free energies $\left(G_{\mathrm{MM}-\mathrm{PB}}\right)$ (see Table $\left.\mathrm{S} 10\right)$ show that solute-solvent interactions destabilize the TS and $\mathbf{P}$ structures with respect to $\mathbf{R} 2$ by 12.9 and $12.5 \mathrm{kcal} / \mathrm{mol}$, respectively. Note that these values are quite close to the QM-SCRF $\Delta \Delta G_{\text {solv }}$ values (12.7 and $11.3 \mathrm{kcal} / \mathrm{mol}$, respectively). This comparison between the QMSCRF and MM-PB results can be seen as a validation test supporting the use of the MM-PB protocol to investigate environmental effects in intramolecular reactions in solution. 
Figure S4. Snapshot of the succinate monoester extracted from the MD-LES simulation.

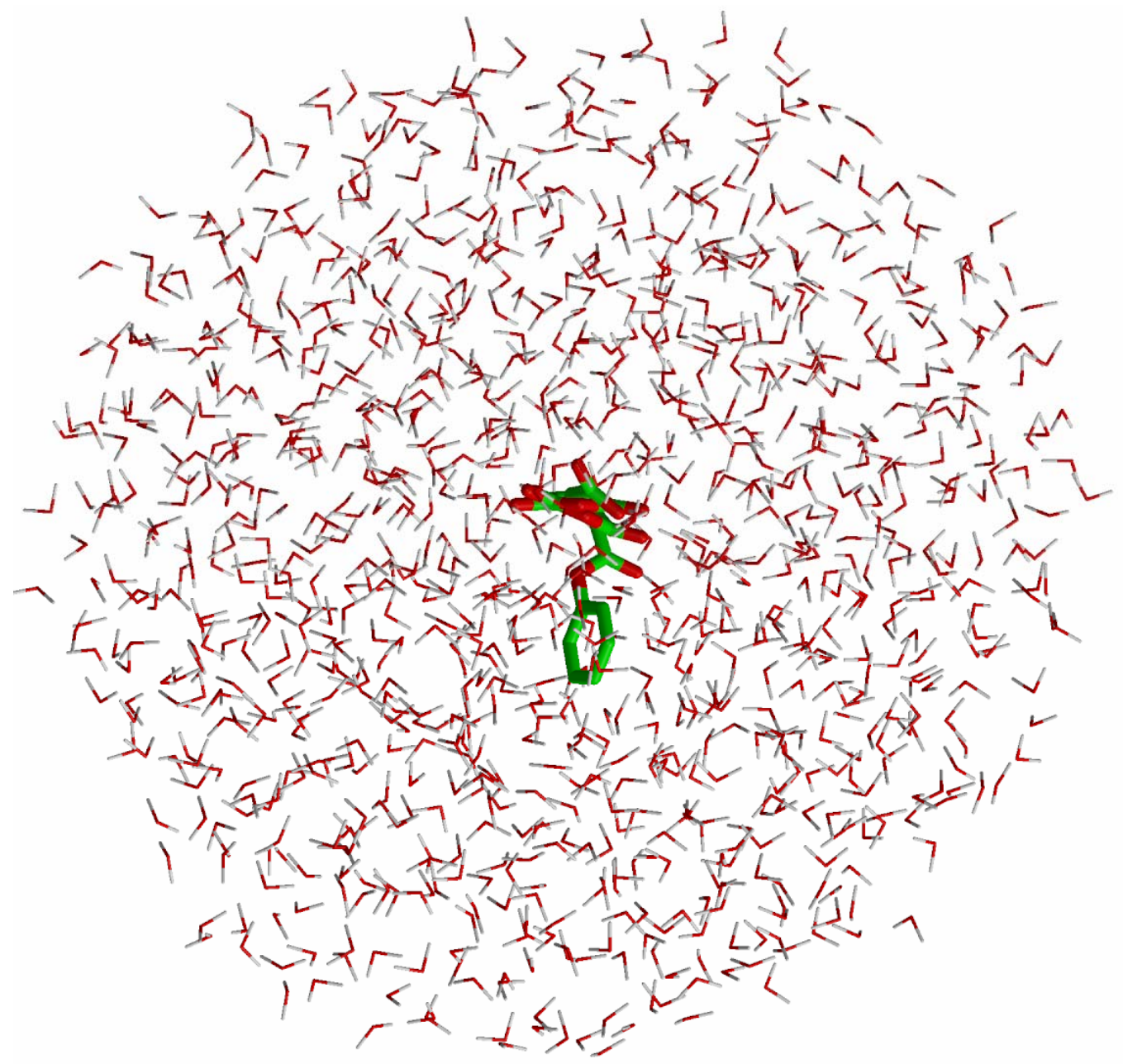


$Q M, M D-L E S$ and MM-PB calculations of the conversion of (-)-chorismate to prephenate catalyzed by chorismate mutase

The chorismate mutase enzyme has become something of a model system for enzymatic reactions as it has been studied extensively by theoreticians using a broad array of computational methods, including DFT and ab initio methods, classical MD, EVB; semiempirical QM/MM, DFT/MM and SCC-TB-DF (54-68). We have chosen the chorismate mutase system as a test of our MD-LES \& MM-PB computational protocol that estimates environmental effects for a series of QM structures relevant to an enzymatic mechanism.

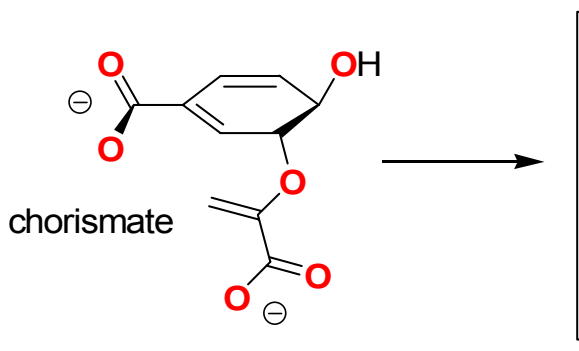

$\mathbf{R}$

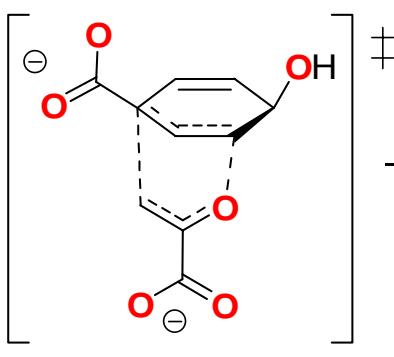

TS

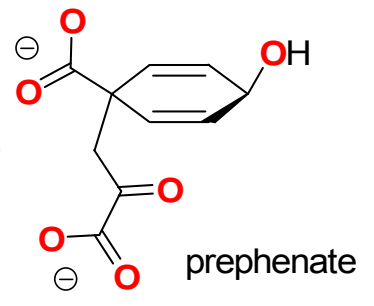

$\mathbf{P}$

\section{Scheme S2}

The chorismate mutase enzyme catalyzes the Claisen rearrangement of (-)chorismate to prephenate without participation of the enzyme groups in the actual chemistry (see Scheme S2). Although there has been much controversy about the nature of the catalytic effect of the chorismate mutase in the recent literature, herein we consider the chorismate mutase enzyme only as a convenient reference for validating the MM-PB calculations.

We started our test calculations by taking the semiempirical QM/MM optimized geometries of the $\mathbf{R}$, TS and $\mathbf{P}$ enzyme-substrate complexes that have reported in previous work.(65) The geometry of the substrate molecule was reoptimized at the 
B3LYP/6-31G* level. To maintain the enzymatic conformation of the reactive groups during the B3LYP/6-31G* optimization, the substrate was surrounded by a solvent continuum with a dielectric constant of 20 . The three critical structures ( $\mathbf{R}$, TS and $\mathbf{P}$ ) were characterized by means of frequency calculations. Single-point B3LYP/6-311+G** calculations in the gas-phase were done on the optimized B3LYP/6-31G* geometries to refine their electronic energies. $H F / 6-31+G^{*}$ RESP atomic charges were derived in order to build the corresponding MM models of the substrate molecule in the $\mathbf{R}$, TS and $\mathbf{P}$ configurations.

To build the solvated enzyme-substrate systems, we extracted one snapshot from the previous MD simulation of the chorismate mutase enzyme from Bacillus subtilis in aqueous solution.(65) The original periodic cubic box constructed by Martí et al. (56 x 56 x $56 \AA^{3}$ ) was enlarged by adding 5118 TIP3P water molecules resulting in a box of dimension $68 \times 68 \times 68 \AA^{3}$. The protein and solvent atoms were represented by the AMBER force field. After having docked the."MM model" of the TS structure, a 500 ps MD simulation was carried out for equilibration with protocols identical to those used for the BuChE system. Subsequently, a 1.0 ns MD-LES simulation was carried out with three different LES copies of the "reactive MM models": the reactant complex (R), the transition structure (TS), and the product complex (P) (see Figure S5). The geometry of each LES copy was linked to its corresponding QM reference structure by applying appropriate RMSD constraints. All the MD trajectories were computed with the SANDER module of the AMBER 7.0 package of programs.

One hundred snapshots were extracted from the last 500 ps of the LES-MD trajectory. The snapshots were processed before carrying out the MM-PB calculations by removing the counterions and most of the waters (only 50 water molecules solvating 
the catalytic site were kept). Finally, we carried out the MM-PB energy calculations on the selected snapshots in order to estimate the average free-energy corrections that take into account the environmental effects on the $\mathbf{R}$, TS and $\mathbf{P}$ QM structures. The computational details of the MM-PB calculations were again identical to those employed for the BuChE systems.

The electronic energies of the QM structures, the average values of the MM-PB free energies and the MM energy components are shown in Table S11. The $G_{\mathrm{MM}-\mathrm{PB}}$ values are the MM-PB free energy corrections to the B3LYP/6-311+G** free energies of the QM models. On going from $\mathbf{R}$ to $\mathbf{T S}$, the environmental effects stabilize the TS structure by $9.2 \mathrm{kcal} / \mathrm{mol}$ whereas the product complex $\mathbf{P}$ becomes destabilized. by 7.7 $\mathrm{kcal} / \mathrm{mol}$. The resulting free energy barrier in the enzyme amounts to $13.7 \mathrm{kcal} / \mathrm{mol}$, which compares quite well with the experimental value of $15.4 \mathrm{kcal} / \mathrm{mol}$ (see Table S11). The product complex, whose approximate free energy in the enzyme is -9.9 below that of $\mathbf{R}$, becomes a stable structure along the reaction profile. Therefore, we conclude that the combination of MD-LES simulations with MM-PB calculations gives a balanced description of the catalysis of the conversion of (-)-chorismate to prephenate. 
Table S11. Relative energy components and free energy corrections (in $\mathrm{kcal} / \mathrm{mol}$ ) of the "QM models" involved in the conversion of (-)-chorismate to prephenate catalyzed by chorismate mutase. The MM-PB energy terms correspond to average values derived from 100 snapshots extracted during the last 500 ps of a MD-LES simulation and post-processed according to the MM-PB computational scheme. Standard error of the mean values are given in parentheses. All values are in $\mathrm{kcal} / \mathrm{mol}$.

\begin{tabular}{cccccccc}
\hline Structure & $\Delta E_{\mathrm{B} 3 \mathrm{LYP}}+G_{\text {therm }}{ }^{\mathrm{a}}$ & $G_{\mathrm{MM}-\mathrm{PB}}{ }^{\mathrm{b}}$ & $E_{\mathrm{MM}}{ }^{\mathrm{c}}$ & $E_{\text {elec }}{ }^{\mathrm{d}}$ & $E_{v d W}{ }^{\mathrm{d}}$ & $E_{\text {internal }}{ }^{\mathrm{d}}$ & 0.0 \\
\hline $\mathbf{R}_{\mathrm{ax}}$ & 0.0 & 0.0 & 0.0 & 0.0 & 0.0 & 0.0 \\
TS & 22.9 & $-9.2(0.5)$ & $-7.7(0.7)$ & $-6.7(0.9)$ & $-0.5(0.6)$ & $-1.5(0.4)$ & $13.7(15.4)^{\mathrm{f}}$ \\
$\mathbf{P}$ & -17.6 & $7.7(0.8)$ & $10.5(0.8)$ & $19.4(1.2)$ & $-8.8(6.4)$ & $-2.8(0.5)$ & -9.9 \\
\hline
\end{tabular}

${ }^{a}$ From single-point $\mathrm{B} 3 \mathrm{LYP} / 6-311+\mathrm{G}^{* *}$ calculations on the QM models including the B3LYP/6-31G* thermal corrections to free energy. Geometries were optimized in a solvent continuum $(\varepsilon=20)$.

${ }^{\mathrm{b}}$ Free energy correction to the QM energies obtained from MM-PB calculations: $G_{\mathrm{MM}-\mathrm{PB}}=E_{\mathrm{MM}}+\Delta \Delta G_{\text {solv }}$

${ }^{c}$ Molecular mechanical correction to the QM energies (HF/6-31+G* RESP charges).

${ }^{\mathrm{d}}$ Electrostatic, van der Waals, and internal (bond-angle-torsional) energy components of the MM energy correction

${ }^{\text {e}}$ Approximate free energy of the small QM models in the enzyme: $\Delta G \approx \Delta E_{B 3 L Y P}+G_{\text {therm }}+G_{\mathrm{MM}-\mathrm{PB}}$

${ }^{\mathrm{f}}$ Experimental free energy barrier. 
Figure S5. Snapshot of the chorismate mutase enzyme from $B$ subtilis extracted from the MD-LES simulation.

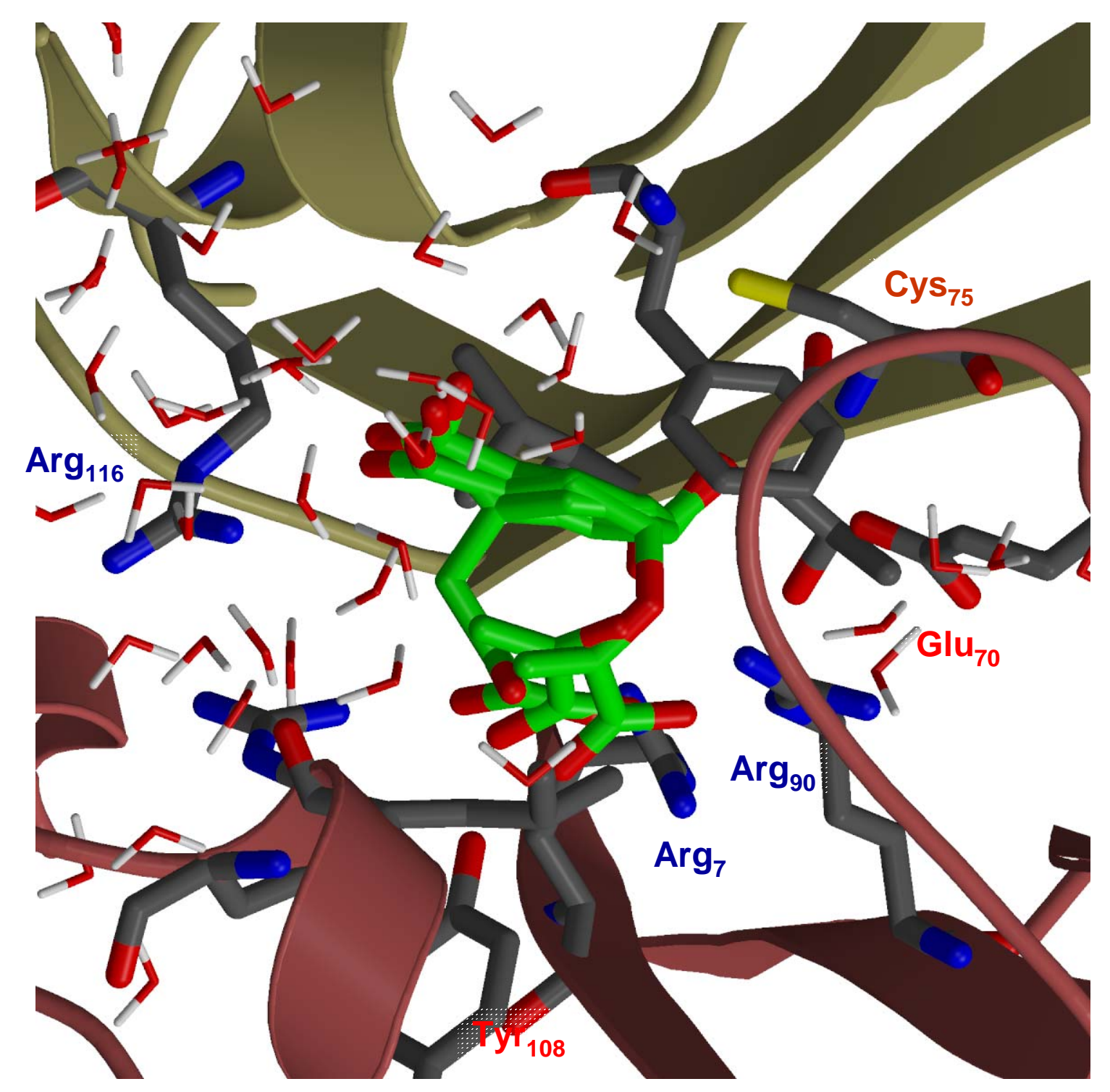


Script, coordinate and data files containing the butyrylcholine and glycerol parameters in a format suitable for the LEaP program

\section{BUTYRYLCHOLINE}

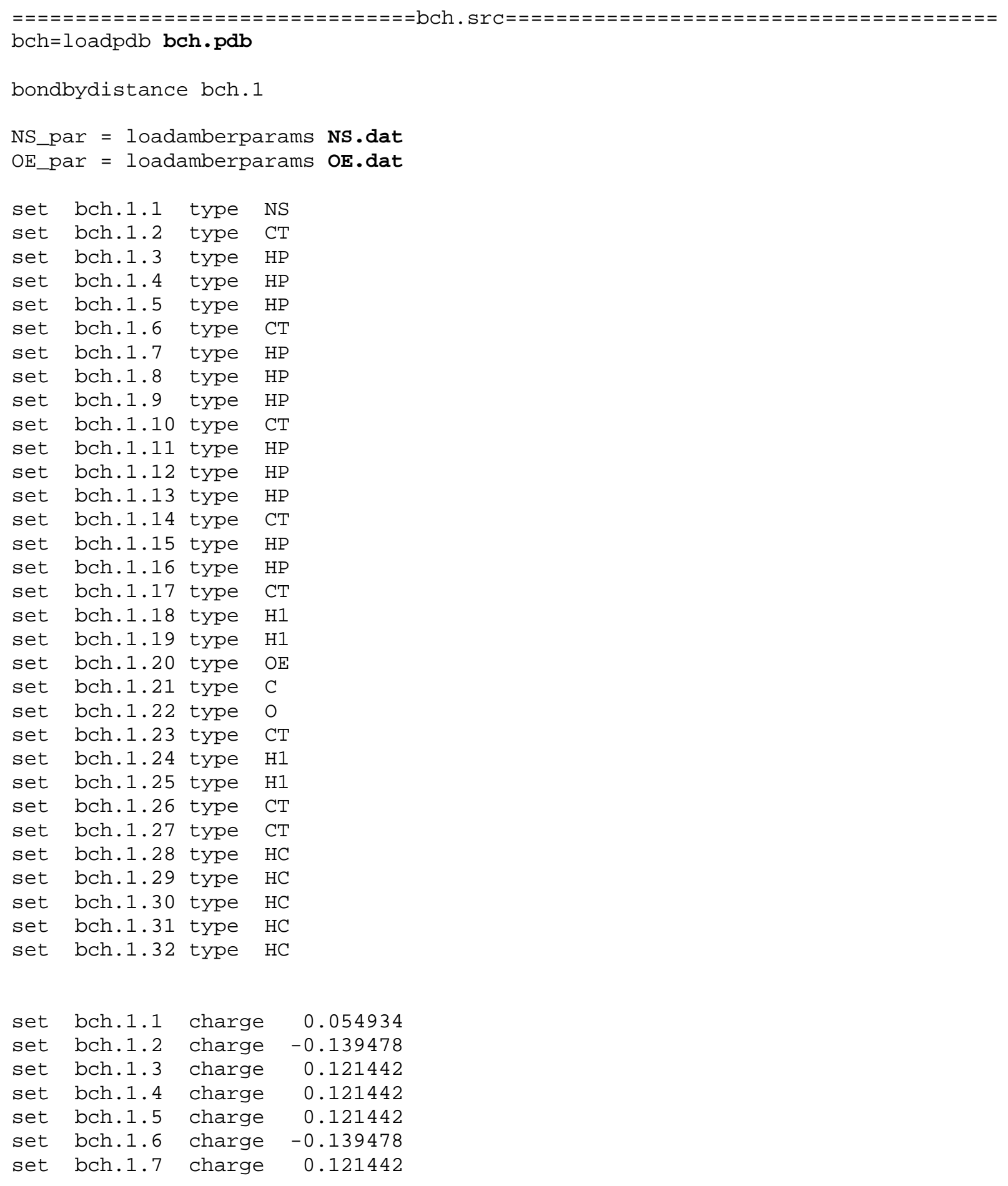




\begin{tabular}{|c|c|c|c|}
\hline th & $\mathrm{ch} 18$ & & 0.121442 \\
\hline et & bch. 1.9 & charge & 0.121442 \\
\hline et & bch.1.10 & charge & -0.139478 \\
\hline & bch.1.11 & charge & $\odot .121442$ \\
\hline & bch.1.12 & charge & 0.121442 \\
\hline & bch.1.13 & charge & 0.121442 \\
\hline & bch.1.14 & charge & $-\odot .097379$ \\
\hline & bch.1.15 & charge & 0.132984 \\
\hline & bch.1.16 & charge & $\odot .132984$ \\
\hline & bch.1.17 & charge & $\odot .007842$ \\
\hline & bch.1.18 & charge & $\odot .128421$ \\
\hline & bch.1.19 & charge & $\odot .128421$ \\
\hline & bch.1.20 & charge & -0.413577 \\
\hline & bch.1.21 & charge & $\odot .695876$ \\
\hline & bch.1.22 & charge & -0.550201 \\
\hline & bch.1.23 & charge & $-\odot .013497$ \\
\hline & bch.1.24 & charge & 0.023037 \\
\hline & bch.1.25 & charge & $\odot .023037$ \\
\hline & bch.1.26 & charge & $\odot .039469$ \\
\hline & bch.1.27 & charge & -0.115784 \\
\hline & bch.1.28 & charge & $\odot .012116$ \\
\hline & bch.1.29 & & 0.012116 \\
\hline & bch. 1.30 & charge & 0.041554 \\
\hline & ch. 1.31 & charge & 0.041554 \\
\hline & ch. 1.32 & 5 & $\odot .041554$ \\
\hline
\end{tabular}

alignaxes bch

check bch

saveamberparm bch bch.top bch.crd quit 


\begin{tabular}{|c|c|c|c|c|c|c|c|c|c|}
\hline ATOM & 1 & N1 & $\mathrm{BCH}$ & 1 & -2.541 & -0.081 & -0.175 & 1.00 & $\odot .0 \odot$ \\
\hline ATOM & 2 & $\mathrm{C} 2$ & $\mathrm{BCH}$ & 1 & -3.903 & 0. 219 & -0.721 & 1.00 & 0.00 \\
\hline ATOM & 3 & H3 & $\mathrm{BCH}$ & 1 & -4.455 & -0.704 & -0.813 & 1.00 & 0.00 \\
\hline ATOM & 4 & $\mathrm{H} 4$ & $\mathrm{BCH}$ & 1 & -4.419 & 0.886 & -0.047 & $1.0 \odot$ & $\odot . \odot \odot$ \\
\hline ATOM & 5 & H5 & $\mathrm{BCH}$ & 1 & -3.802 & 0.682 & -1.691 & 1.00 & 0.00 \\
\hline ATOM & 6 & C6 & $\mathrm{BCH}$ & 1 & -2.691 & -0.709 & 1.177 & 1.00 & 0.00 \\
\hline ATOM & 7 & $\mathrm{H} 7$ & $\mathrm{BCH}$ & 1 & -3.340 & -1.567 & 1.083 & $1.0 \odot$ & $\odot . \odot \odot$ \\
\hline ATOM & 8 & H8 & $\mathrm{BCH}$ & 1 & -3.136 & 0.009 & 1.850 & 1.00 & 0.00 \\
\hline ATOM & 9 & H9 & $\mathrm{BCH}$ & 1 & -1.724 & -1.022 & 1.535 & $1.0 \odot$ & $\odot . \odot \odot$ \\
\hline ATOM & 10 & C10 & $\mathrm{BCH}$ & 1 & -1.871 & -1.052 & -1.098 & 1.00 & $\odot .0 \odot$ \\
\hline ATOM & 11 & H11 & $\mathrm{BCH}$ & 1 & -2.531 & -1.894 & -1.240 & 1.00 & $\odot . \odot \odot$ \\
\hline ATOM & 12 & $\mathrm{H} 12$ & $\mathrm{BCH}$ & 1 & -1.687 & -0.568 & -2.045 & 1.00 & $\odot .0 \odot$ \\
\hline ATOM & 13 & H13 & $\mathrm{BCH}$ & 1 & -0.954 & -1.391 & -0.655 & 1.00 & 0.00 \\
\hline ATOM & 14 & C14 & $\mathrm{BCH}$ & 1 & -1.797 & 1.235 & -0.097 & 1.00 & 0.00 \\
\hline ATOM & 15 & H15 & $\mathrm{BCH}$ & 1 & -2.461 & 1.913 & 0.421 & 1.00 & 0.00 \\
\hline ATOM & 16 & H16 & $\mathrm{BCH}$ & 1 & -1.681 & 1.584 & -1.113 & 1.00 & 0.00 \\
\hline ATOM & 17 & C17 & $\mathrm{BCH}$ & 1 & -0.453 & 1.286 & 0.619 & 1.00 & 0.00 \\
\hline ATOM & 18 & H18 & $\mathrm{BCH}$ & 1 & -0.243 & 2.340 & 0.747 & 1.00 & 0.00 \\
\hline ATOM & 19 & H19 & $\mathrm{BCH}$ & 1 & -0.481 & 0.827 & 1.592 & 1.00 & $\odot .0 \odot$ \\
\hline ATOM & 20 & 020 & $\mathrm{BCH}$ & 1 & 0.615 & 0.772 & -0.143 & 1.00 & 0.00 \\
\hline ATOM & 21 & $\mathrm{C} 21$ & $\mathrm{BCH}$ & 1 & 1.211 & -0.363 & 0.254 & 1.00 & 0.00 \\
\hline ATOM & 22 & 022 & $\mathrm{BCH}$ & 1 & 0.704 & -1.088 & 1.052 & 1.00 & 0.00 \\
\hline ATOM & 23 & $\mathrm{C} 23$ & $\mathrm{BCH}$ & 1 & 2.534 & -0.579 & -0.422 & 1.00 & $0.0 \odot$ \\
\hline ATOM & 24 & $\mathrm{H} 24$ & $\mathrm{BCH}$ & 1 & 2.787 & -1.625 & -0.311 & 1.00 & 0.00 \\
\hline ATOM & 25 & $\mathrm{H} 25$ & $\mathrm{BCH}$ & 1 & 2.429 & -0.352 & -1.477 & 1.00 & 0.00 \\
\hline ATOM & 26 & $\mathrm{C} 26$ & $\mathrm{BCH}$ & 1 & 3.631 & $\odot .309$ & ๑. 195 & 1.00 & $\odot .0 \odot$ \\
\hline ATOM & 27 & $\mathrm{C} 27$ & $\mathrm{BCH}$ & 1 & 4.987 & 0.068 & -0.464 & 1.00 & 0.00 \\
\hline ATOM & 28 & $\mathrm{H} 28$ & $\mathrm{BCH}$ & 1 & 3.699 & 0.102 & 1.259 & 1.00 & 0.00 \\
\hline ATOM & 29 & $\mathrm{H} 20$ & $\mathrm{BCH}$ & 1 & 3.350 & 1.352 & ๑. . 889 & 1.00 & $\odot .0 \odot$ \\
\hline ATOM & 30 & H30 & $\mathrm{BCH}$ & 1 & 4.953 & ○. 292 & -1.526 & 1.00 & $\odot .0 \odot$ \\
\hline ATOM & 31 & H31 & $\mathrm{BCH}$ & 1 & 5.303 & -0.963 & -0.348 & 1.00 & 0.00 \\
\hline ATOM & 32 & H32 & $\mathrm{BCH}$ & 1 & 5.745 & 0.700 & -0.016 & 1.00 & 0.00 \\
\hline
\end{tabular}




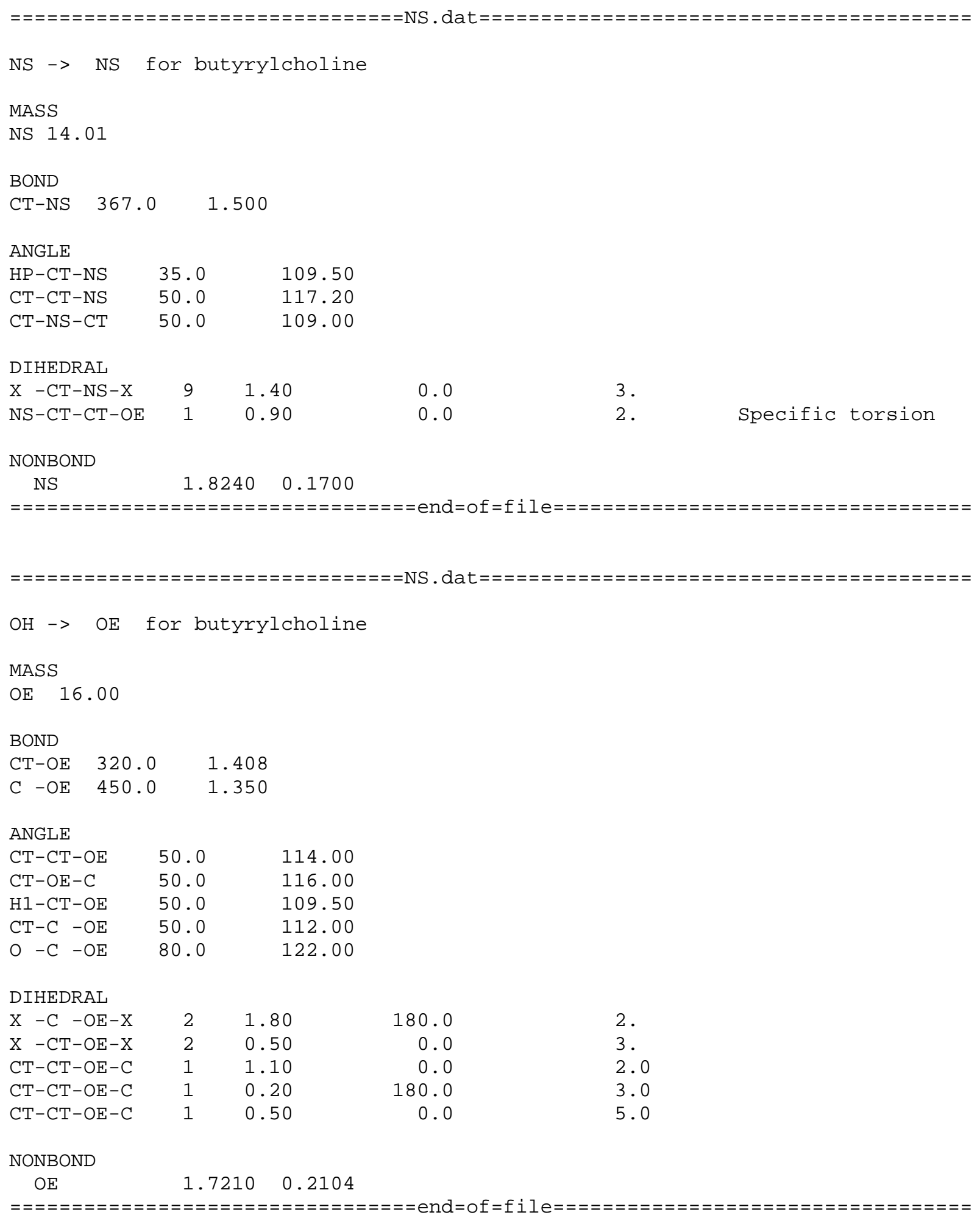




\section{GLYCEROL}

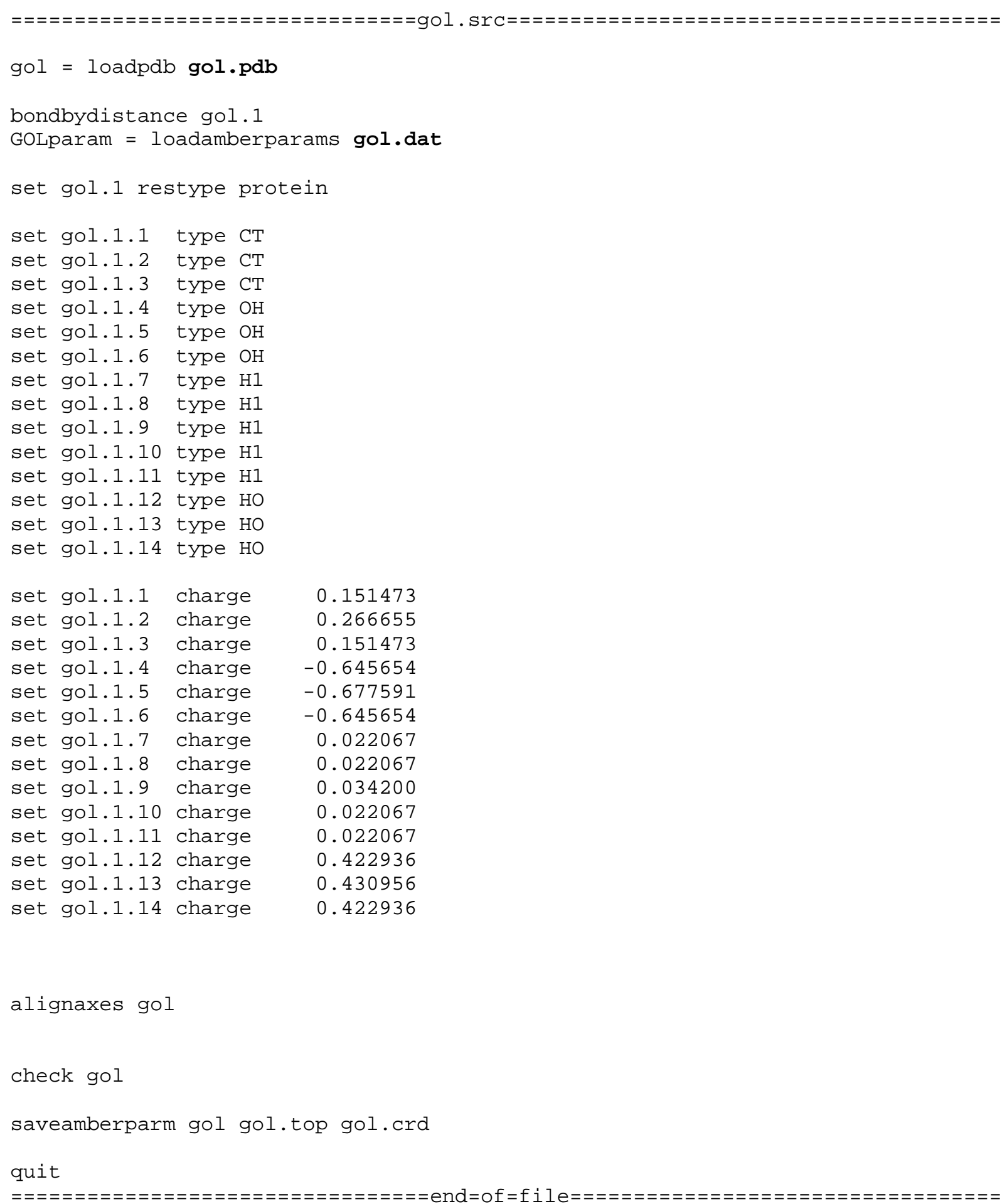




\begin{tabular}{|c|c|c|c|c|c|c|c|c|c|}
\hline ATOM & 1 & $\mathrm{C} 1$ & GOL & 1 & 133.440 & 116.298 & 38.699 & 1.00 & 0.00 \\
\hline ATOM & 2 & $\mathrm{C} 2$ & GOL & 1 & 133.087 & 117.609 & 39.451 & 1.00 & 0.00 \\
\hline ATOM & 3 & $\mathrm{C} 3$ & GOL & 1 & 132.754 & 117.352 & 40.946 & 1.00 & 0.00 \\
\hline ATOM & 4 & 04 & GOL & 1 & 134.606 & 115.685 & 39.268 & 1.00 & 0.00 \\
\hline ATOM & 5 & 05 & GOL & 1 & 134.195 & 118.517 & 39.333 & 1.00 & 0.00 \\
\hline ATOM & 6 & 06 & GOL & 1 & 131.622 & 116.479 & 41.065 & 1.00 & 0.00 \\
\hline ATOM & 7 & $\mathrm{H} 7$ & GOL & 1 & 133.633 & 116.532 & 37.649 & 1.00 & 0.00 \\
\hline ATOM & 8 & H8 & GOL & 1 & 132.599 & 115.604 & 38.753 & 1.00 & 0.00 \\
\hline ATOM & 9 & H9 & GOL & 1 & 132.213 & 118.057 & 38.967 & 1.00 & $\odot .0 \odot$ \\
\hline ATOM & 10 & $\mathrm{H} 10$ & GOL & 1 & 132.520 & 118.303 & 41.430 & 1.00 & $\odot .0 \odot$ \\
\hline ATOM & 11 & $\mathrm{H} 11$ & GOL & 1 & 133.616 & 116.905 & 41.445 & 1.00 & 0.00 \\
\hline ATOM & 12 & $\mathrm{H} 12$ & GOL & 1 & 134.764 & 114.873 & 38.741 & 1.00 & 0.00 \\
\hline ATOM & 13 & H13 & GOL & 1 & 133.896 & 119.372 & 39.711 & 1.00 & 0.00 \\
\hline ATOM & 14 & $\mathrm{H} 14$ & GOL & 1 & 131.473 & 116.365 & 42.028 & 1.00 & $\odot . \odot \odot$ \\
\hline
\end{tabular}

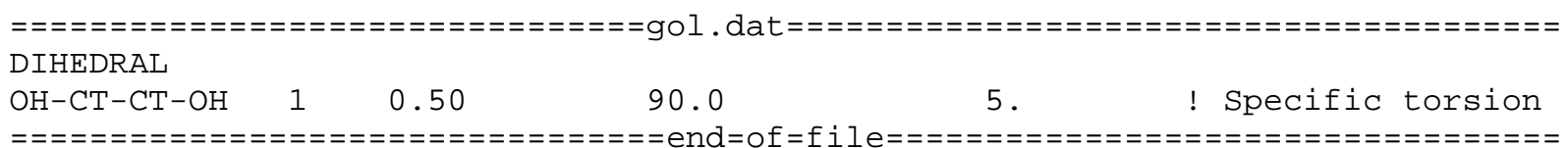




\section{References}

(50) Chipot, C. (2002) Rational determination of charge distributions for free energy calculations. J. Comput. Chem. 24, 409-415.

(51) Duan, Y., Wu, C., Chowdhury, S., Lee, M. C., Xiong, G., Zhang, W., Yang, R., Cieplak, P., Luo, R., Lee, T., Caldwell, J. W., Wang, J., and Kollman, P. A. (2003) A point-charge force field for molecular mechanics simulations of proteins based on condensed-phase quantum mechanical calculations. J. Comput. Chem. 24, 1999-2012.

(52) Bruice, T. C., and Turner, A. (1970) Solvation and approximation. Solvent effects on the bimolecular and intramolecular nucleophilic attack of carboxyl anion on phenyl esters. J. Am. Chem. Soc. 92, 3422-3428.

(53) Peräkylä, M., and Kollman, P. A. (1999) Ab initio quantum mechanical and molecular dynamical study of intra- and intermolecular anhydride formation. $J$. Phys. Chem.A 103, 8067-8074.

(54) Martí, S., Andrés, J., Moliner, V., Silla, E., Tuñón, I., Bertrán, J., and Field, M. J. (2001) A hybrid potential reaction path and free energy study of the chorismate mutase reaction. J. Am. Chem. Soc. 123, 1709-1712.

(55) Worthington, S. E., and Krauss, M. (2001) The claisen rearrangement of an unusual substrate in chorismate mutase. J. Phys. Chem. B 105, 7096-7098.

(56) Guo, H., Cui, Q., Lipscomb, W. N., and Karplus, M. (2001) Substrate conformational transitions in the active site of chorismate mutase: Their role in the catalytic mechanism. Proc. Nat. Acad. Sci. 98, 9032-9037.

(57) Hur, S., and Bruice, T. C. (2002) The mechanism of catalysis of the chorismate to prephenate reaction by the Escherichia coli mutase enzyme. Proc. Nat. Acad. Sci. 99, 1176-1181.

(58) Guimarães, C. R. W., Repasky, M. P., Chandrasekhar, J., Tirado-Rives, J., and Jorgensen, W. L. (2003) Contributions of conformational compression and preferential transition state stabilization to the rate enhancement by chorismate mutase. J. Am. Chem. Soc. 125, 6892-6899.

(59) Repasky, M. P., Guimarães, C. R. W., Chandrasekhar, J., Tirado-Rives, J., and Jorgensen, W. L. (2003) Investigation of solvent effects for the Claisen rearrangement of chorismate to prephenate: Mechanistic interpretation via near attack conformations. J. Am. Chem. Soc. 125, 6663-6672.

(60) Bruice, T. C., and Hur, S. (2003) Comparison of formation of reactive conformers (NACs) for the claisen rearrangement of chorismate to prephenate in water and in the E. coli mutase: The efficiency of the enzyme catalysis. J. Am. Chem. Soc. 125, 5964-5972.

(61) Strajbl, M., Shurki, A., Kato, M., and Warshel, A. (2003) Apparent NAC effect in chorismate mutase reflects electrostatic transition state stabilization. J. Am. Chem. Soc. 125, 10228-10237.

(62) Hur, S., and Bruice, T. C. (2003) The near attack conformation approach to the study of the chorismate to prephenate reaction. Proc. Nat. Acad. Sci. 100, 12015-12020. 
(63) Hur, S., and Bruice, T. C. (2003) Enzymes do what is expected (chalcone isomerase versus chorismate mutase). J. Am. Chem. Soc. 125, 1472-1473.

(64) Hur, S., and Bruice, T. C. (2003) Just a near attack conformer for catalysis (chorismate to prephenate rearrangements in water, antibody, enzymes, and their mutants). J. Am. Chem. Soc. 125, 10540-10542.

(65) Martí, S., Andres, J. L., Moliner, V., Silla, E., Tuñón, I., and Bertrán, J. (2004) A comparative study of Claisen and cope rearrangements catalyzed by chorismate mutase. An insight into enzymatic efficiency: Transition state stabilization or substrate preorganization? J. Am. Chem. Soc. 126, 311-319.

(66) Zhang, X., Zhang, X., and Bruice, T. C. (2005) A definitive mechanism for chorismate mutase. Biochemistry 44, 10443-10448.

(67) Crespo, A., Martí, M. A., Estrin, D. A., and Roitberg, A. E. (2005) Multiple-steering QM-MM calculation of the free energy profile in chorismate mutase. J. Am. Chem. Soc. 127, 6940-6941.

(68) Ishida, T., Fedorov, D. G., and Kitaura, K. (2006) All electron quantum chemical calculation of the entire enzyme system confirms a collective catalytic device in the chorismate mutase reaction. J. Phys. Chem. B 110, 1457-1463. 